\title{
humanidades
}

Revista humanidades

Enero-Junio, 2015 • Volumen 5, Número 1・ISSN 2215-3934• pp. 1-18

\section{El acto de habla de la diatriba de hablante femenino en un contexto matrimonial en crisis: el caso de Diatriba de amor contra un hombre sentado, de Gabriel García Márquez}

DOI: http://dx.doi.org/10.15517/h.v5i1.19381

Recibido: 12-Junio-2014 / Aceptado: 29-Julio-2014

\section{Dorde Cuvardic García}

Doctor, profesor Catedrático en la Escuela de Filología, Lingüística y

Literatura y en la Escuela de Ciencias de la Comunicación Colectiva de la Universidad de Costa Rica.

Correo electrónico: dcuvardic@yahoo.es

Más sobre el autor:

Todos los derechos reservados. Universidad de Costa Rica. Esta revista se encuentra licenciada con Creative Commons Reconocimiento-NoComercial-SinObraDerivada 3.0 Costa Rica.

Correo electrónico: humanidades.eeg@ucr.ac.cr / Sitio web: http:/ / revistas.ucr.ac.cr/index.php/humanidades 


\section{El acto de habla de la diatriba de hablante femenino en un contexto matrimonial en crisis: el caso de Diatriba de amor contra un hombre sentado, de Gabriel García Márquez}

\section{Resumen}

El monólogo teatral siempre ha expresado las confesiones íntimas de sus hablantes.

Palabras clave:

Es la función que también adquiere en Diatriba de amor contra un hombre

Diatriba, Gabriel

sentado, la única obra teatral de Gabriel García Márquez y uno de los textos del autor colombiano que menor atención crítica ha recibido. El propósito del presente artículo es analizar este monólogo desde la pragmática literaria, entendiendo la diatriba como un acto de habla expresivo determinado por los papeles de sus protagonistas y por los específicos recursos enunciativos, temáticos y retóricos utilizados por el hablante. En el texto que nos ocupa, la diatriba es emitida por una esposa, en el marco de una crisis matrimonial. Como denuncia del machismo de la cultura patriarcal latinoamericana, se puede entender, en consecuencia, como una resemantización feminista de las tradicionales diatribas misóginas.

\section{The speech act rant female speaker in a marital crisis context: The case of Diatriba de amor contra un hombre sentado, by Gabriel Garcia Marquez.}

\footnotetext{
Abstract

Speakers through theatrical monologue have always expressed their intimate confessions. This function is also acquired in Diatriba de amor contra un hombre sentado, Gabriel García Márquez's only dramatic work, and one of the Colombian writer's texts which have received less critical attention. The purpose of this article is to analize this monologue from a literary pragmatics point of view, understanding diatribe as an expressive speech act, determined by the leading actors roles, and through specific enunciative, thematic and rhetoric resources used by the speaker. In this text, diatribe is used by a wife, in a marriage crisis setting. As a denouncement of machismo in the Latin American patriarchal culture, it can therefore be understood as a feminist resemantization of traditional misogynist diatribes.
} 
Diatriba de amor contra un hombre sentado (1988, fecha de su estreno), de Gabriel García Márquez, ocupa un lugar singular en su extensa producción literaria. Es su única obra dramática y una de las pocas en las que el personaje protagonista es femenino1. Además, es una de las obras del autor colombiano que menor atención crítica ha recibido. Como medio para iniciar los estudios críticos sobre este texto teatral, el presente artículo, como principal objetivo, busca analizarlo e interpretarlo desde la intersección de dos propuestas, la teoría pragmática de los actos de habla y los estudios de género.

\section{Introducción}

Es un caso de diatriba transgénero. El autor es un hombre, Gabriel García Márquez, mientras que la voz enunciativa del monólogo corresponde al personaje de Graciela, que además propone un discurso reivindicativo de tono feminista ${ }^{2}$. En todo caso, no es el único texto del autor colombiano cuyo narrador intradiegético protagonista es una mujer. Monólogo de Isabel viendo llover en Macondo (1968) también utiliza, valga la redundancia, la modalidad de monólogo - esta vez en la narrativa- de hablante femenino.

La orientación enunciativa y temática aparece en el mismo título de esta producción dramática. Es una diatriba de hablante femenino en un contexto matrimonial en crisis. Aunque parezca paradójico, es una diatriba de amor, como reza el mismo título: este acto de habla no podría emitirse si existiera indiferencia en la relación que tiene Graciela con su marido. Para que se enuncie la diatriba de una esposa 'contra' su pareja debe existir una relación de amor-odio hacia esta última.

Sobre las relaciones de género en la producción de García Márquez contamos con la contribución de Solomon (1993, p. 192-205). Este crítico ha señalado que los roles asumidos por los personajes femeninos en Cien años de soledad (1967) son los típicos de la sociedad patriarcal latinoamericana: se acoplan a los clásicos estereotipos prescritos por la ideología del marianismo, reducidos a la esfera 
privada, el hogar y la maternidad. Sin negar que en ocasiones, en la historia de la literatura, exista una equivalencia entre la ideología del autor, por una parte, y la del narrador y personaje, por otra, el problema que ofrece la interpretación de este crítico consiste en considerar que la visión de mundo patriarcal que predomina en la ficción representada (Macondo) debe ser necesariamente la ideología defendida por el escritor, García Márquez. Es decir, atribuye al autor una ideología que, en realidad, pertenece a la estructura de las relaciones sociales de los personajes en el mundo representado. Este es un problema metodológico que suele presentarse en muchos análisis literarios: proyectar la ideología del enunciado al ámbito de la enunciación. Concluye que el novelista colombiano suscribe un punto de vista machista por el hecho de que los personajes femeninos de Cien años de soledad afronten predominantemente papeles típicos de una sociedad patriarcal, sin considerar la posibilidad de que esta representación constituya, en realidad, una denuncia de las relaciones de género en la sociedad latinoamericana tradicional. El punto de vista patriarcal en un autor debe establecerse, más bien, a partir de la valoración que otorgue al mundo representado, machista y androcéntrico.

Aunque la teoría de los actos de habla se ha utilizado sobre todo para reflexionar sobre el estatuto de la literatura -sobre la literariedad- como acto discursivo, también es un recurso que la crítica literaria puede utilizar a la hora de analizar de enunciación de las voces ficcionales en los textos literarios. Si bien John Austin (2009, p. 151) considera que la literatura es un acto 'no serio' o 'fallido', debe precisarse que este filósofo formula esta afirmación desde las intenciones emitidas por hablantes que protagonizan el circuito de la comunicación oral. Si un hablante dirige al interlocutor un relato ficticio, es evidente que el acto no es 'serio', en el sentido de que no busca modificar la conducta del oyente (aunque sí puede incidir, con el relato que este último escucha, en su disfrute estético y en su visión de mundo). Pero Austin no toma en cuenta que el mundo ficcional se encuentra regido por sus propios principios de autenticidad, y que los actos discursivos emitidos

\section{El acto de habla de la diatriba como objeto de estudio literario}


por sus posibles hablantes - es decir, los personajes- son 'serios', es decir, están regidos por el criterio de autenticidad: los personajes emiten actos de habla 'serios', ya que actúan y hablan para determinar la conducta de los demás personajes y, por lo tanto, los acontecimientos del mundo en el que viven. Por ejemplo, una queja proferida por un personaje sobre otro en el mundo ficcional en el que ambos vivan, es emitida intencionalmente por este hablante imaginario con el objetivo de obtener una disculpa o reparación del interlocutor y, como tal, tiene consecuencias en las relaciones que establezcan entre sí ambos personajes. En el caso de la obra teatral de García Márquez, la diatriba es emitida ‘seriamente’ por Graciela desde la búsqueda de ciertos objetivos, que serán analizados a lo largo de este artículo.

La teoría de los actos de habla todavía no ha sido utilizada suficientemente para identificar y analizar en los textos literarios las acciones lingüísticas emitidas por diferentes enunciadores ficcionales. Considero que, como recurso analítico, puede ser empleada esta aproximación para estudiar el poema "Salutación del optimista", de Cantos de vida y esperanza (1905), de Rubén Darío, donde el enunciador realiza el acto de habla de la salutación o saludo, o el poema "Al partir", de Gertrudis Gómez de Avellaneda, donde el yo-lírico realiza la acción de despedir. Lo mismo se puede argumentar sobre la emisión de la acción lingüística que nos ocupa en el presente artículo. Si bien no existe el verbo 'diatribar', sí podemos hablar, en cambio, de la acción de 'emitir una diatriba', en el presente caso expresada por el personaje de Graciela.

La diatriba de García Márquez pertenece a la modalidad temática que Pavis (1998, p. 298) define como monólogo de reflexión o de decisión: "Colocado frente a una decisión delicada, el personaje se presenta a sí mismo los argumentos y los contraargumentos de una conducta". Emitida en un momento de crisis matrimonial, la voz enunciativa -hacia el final de esta diatriba-, toma una decisión: separarse de su marido. El monólogo sirve para expresar pensamientos reprimidos, sopesar dilemas y reflexionar sobre las ventajas y desventajas de la decisión por adoptar. 
La diatriba incorpora el discurso ajeno para someterlo a crítica ${ }^{3}$. En la Diatriba de amor contra un hombre sentado, el lector o espectador obtiene indicadores del discurso y la conducta patriarcal del esposo durante los largos años de matrimonio a partir de las 'huellas' que deja en el discurso de Graciela. Como sucede en la estructura argumentativa de todo monólogo, el discurso del hablante se hace eco del discurso de su destinatario: en el caso que nos ocupa, la esposa incorpora la conducta patriarcal protagonizada por su marido durante la vida matrimonial con el fin de enjuiciarla. No responde al discurso actual de su marido, ya que en el presente de la enunciación se encuentra en silencio.

Considero que Diatriba de amor contra un hombre sentado también responde a una modalidad específica de monólogo, desde el punto de vista enunciativo, el soliloquio, que Pavis (1998, p. 297), define como un "discurso dirigido a un interlocutor que permanece mudo." El pretendido interlocutor de Graciela es su marido, pero, en realidad, no espera respuesta, ni siquiera que su diatriba sea escuchada, acostumbrada como está, después de muchos años, al desprecio y silencio del esposo ${ }^{4}$.

En el mundo ficcional en el que viven los personajes, el marido de Graciela es un ser humano de carne y hueso, mientras que en el circuito comunicativo establecido entre el escenario y el público presente en la sala (si llegase a escenificarse esta obra), se convierte es un maniquí, tal como indican las didascalias de la edición de Mondadori. A García Márquez le interesa que los espectadores aprecien la actitud indiferente del marido. El símbolo que mejor muestra esta personalidad afectivamente distanciada es el 'maniquí'. El marido es tan 'sordo' a sus reivindicaciones como un objeto inanimado, como un muñeco.

La categoría enunciativa - el soliloquio- y la pragmática - la diatriba- quedan estrechamente vinculadas en el habla de Graciela. El primero, el soliloquio, siempre 
ha cumplido la función de expresar las confesiones íntimas de los hablantes. Y entre estas confesiones -bastante imbuidas de tácticas pertenecientes a la llamada 'descortesía verbal'- se encuentran la diatriba, consistente en una serie de 'reproches' proferidos contra un interlocutor. El carácter de agresión verbal de esta última se hace evidente en la definición que ofrece el diccionario de la Real Academia Española (I, 817): "Discurso o escrito violento e injurioso contra alguien o algo".

La diatriba pertenece al grupo de los actos de habla expresivos (según la tipología de Searle -1975-, son todos aquellos que tienen por intención expresar la existencia del estado psicológico interno de un hablante). Como acto de habla, Diatriba de amor contra un hombre sentado se puede analizar desde las siguientes categorías de análisis:

- la posición social del enunciador y el tipo de relación interpersonal que tiene frente al interlocutor,

- la posición social e interpersonal del interlocutor frente al hablante ,

- la estilística (sintaxis) del acto de habla proferido,

- su temática (semántica),

- su intencionalidad (los objetivos que se buscan mediante su expresión),

- su medio (oral o escrito),

- su duración,

- y sus consecuencias.

Desde estas categorías se analizará e interpretará la Diatriba de amor contra un hombre sentado, de García Márquez.

La diatriba ha estado estrechamente vinculada a la historia de la literatura misógina en Occidente, en géneros de enunciación masculina. Es conocida su presencia, 
por ejemplo, en la literatura de la Antigüedad y de la Edad Media ${ }^{5}$. Partiendo de esta tradición, García Márquez resemantiza uno de los sentidos con los que ha estado tradicionalmente asociada, el de ataque verbal a la mujer. Frente a las de intencionalidad misógina, la diatriba emitida por Graciela se caracteriza por el ataque verbal a un hombre machista y por la crítica del patriarcado. Con este propósito, el personaje femenino expone una serie de acusaciones contra el símbolo masculino de este poder patriarcal en las relaciones de pareja: la figura del esposo.

Si bien es preciso reconocer que toda obra teatral es, por lo general, un montaje o conglomerado de actos de habla ilocutivos y de acciones físicas y que es más difícil reconocer, en su integridad, un único acto comunicativo global (Schaeffer, 2006, p. 73), en ocasiones, sobre todo en textos cuya fuente enunciadora no cambia (es decir, en los que no se presentan diversos turnos de habla, como en el caso del soliloquio), se puede discriminar un único acto de habla comunicativo o ilocutivo global. Así ocurre en el texto de García Márquez, donde Graciela emite lugar un único acto de habla global: una diatriba.

Se inicia la diatriba cuando Graciela y su esposo llegan al espacio privado del hogar, una vez que disimularon sus 'diferencias' durante una cena fuera de casa. La didascalia inicial informa: "El drama transcurre en una ciudad del Caribe con treinta y cinco grados a la sombra y noventa por ciento de humedad relativa, después que Graciela y su marido regresan de una cena informal poco antes del amanecer del 3 de agosto de 1978"6. La diatriba de una persona que ha quedado 'amordazada' durante largo tiempo debe encontrar una ocasión propicia para expresarse: la madrugada es un momento liminal desprovisto de los usos sociales diurnos y Graciela, en este momento, no es ama de casa ni esposa: es simplemente una mujer. Una importante obra del teatro y del cine norteamericano también nos ofrece la manifestación de las diferencias matrimoniales en la 'altas horas' de la noche, después de la participación de los esposos en una reunión social: Quién teme

\section{Análisis de la diatriba feminista de Graciela}


a Virginia Woolf, del dramaturgo Edward Albee (1962), adaptada al cine por Mike Nichols (1966).

Graciela procede, en este momento, a quitarse la 'fachada social' que ofreció en la cena informal, que imponía la exhibición pública de relaciones cordiales con su esposo. Su primera acción es quitarse el maquillaje, que también puede entenderse en términos simbólicos. El inicio de su discurso, además de responder a la intencionalidad de un buen incipit -el de ser programador de lectura del discurso subsiguiente-, también alude a la 'fachada' de felicidad que toda relación matrimonial debe ofrecer ante los demás: “ ¡Nada se parece tanto al infierno como un matrimonio feliz!'(11). La aparente contradicción de esta paradoja se resuelve como el lector infiere su sentido denotativo o literal: nada se parece tanto a un 'infierno sentimental' como un matrimonio que públicamente proyecta una imagen feliz de cara a los valores pregonados por la cultura hegemónica patriarcal. Una vez eliminada esta máscara, cuando Graciela desarrolle su diatriba, ya habrá desaparecido toda impostura.

La diatriba implica la intención del hablante de ser honesto con el interlocutor. En este acto de habla, el enunciador procede a realizar una serie de confesiones y de reivindicaciones desde el principio de la sinceridad: la mentira y la mala fe no son conductas de este tipo de enunciadores ${ }^{7}$. Ante su marido y ante el público lector o espectador, Graciela desnudará su intimidad y su estado psicológico y moral, caracterizado por el hastío que le produce una relación matrimonial sostenida 'artificialmente' a través del tiempo. Abandona la hipocresía social, la cortesía verbal.

Graciela y su esposo pertenecen a la esfera de la alta burguesía latinoamericana, más particularmente de la colombiana. La diatriba de la esposa no solo se formula 
contra el patriarcado, sino también contra el estilo de vida del 'nuevo rico' protagonizado por su corrupto marido: "No quiero saber nada más de heráldicas inventadas, ni de falsos retratos de bisabuelos falsos pintados por falsos Velázquez, ni de carretadas de votos comprados para políticos matreros" (64). La compra de títulos nobiliarios es un tópico recurrente en las representaciones literarias de los 'nuevos ricos', tanto españoles (novelas de Galdós) como latinoamericanos (la burguesía habanera de La consagración de la primavera, de Alejo Carpentier), cuya conducta básica se basa en el 'aparentar'. La Teoría de la clase ociosa (1899), de Thorstein Veblen, nos permite conocer la posición que ocupa el papel o rol de esposa en estas esferas sociales: forma parte de los signos de ostentación del marido, que orienta su conducta hacia la exhibición de signos de pertenencia a la burguesía. En su diatriba, Graciela critica el hecho de haberse convertido ella misma, como esposa, durante toda su vida matrimonial, en parte de estos signos. Aunque pertenece a los sectores hegemónicos, desde el punto de vista de la estructura clasista en América Latina, este personaje femenino detenta un papel subordinado desde el punto de vista del patriarcado. Como esposa, ocupa un lugar improductivo, vinculada a actividades no utilitarias.

¿Qué tematiza Graciela, enunciadora de la diatriba? En primer lugar, hace un recuento de su biografía: el noviazgo y el matrimonio. Evalúa el comportamiento de su esposo en una recapitulación de hechos. De ahí que no solo se ofrezca el presente de la enunciación del soliloquio. En ocasiones, del relato de los acontecimientos pasados se pasa, mediante su actualización, a su representación, mostración o escenificación directa. Introducidos mediante didascalias, se escenifican episodios clave en la vida de la pareja, a medida que Graciela los va incorporando en su diatriba.

Otro tema ineludible en la diatriba de hablante femenino en contexto matrimonial consiste en mostrar que la esposa siempre estuvo al tanto de la infidelidad del 
marido: "Durante años me aguanté los papelitos anónimos que me metían por debajo de las puertas o en el parabrisas del automóvil [...]" (46). Además, en la diatriba matrimonial es común que el hablante asuma como una venganza contra el interlocutor la exhibición de episodios desconocidos por este último, situaciones cuyo conocimiento, en principio, le pueden provocar un daño moral. En este sentido, Graciela comunica a su esposo secretos que hasta este momento no había confesado: es el caso de su 'romance' con Floro Morales.

La diatriba de Graciela también supone una recapitulación de la vida matrimonial. La decisión de separarse es consecuencia directa del enjuiciamiento negativo al que somete su revisión biográfica: "Me voy por mí, y por nadie más, harta de una suerte mezquina que me lo ha dado todo menos el amor" (72). Pero no solo Graciela enjuicia su matrimonio, sino que también reevalúa su noviazgo, apreciado desde el presente de la enunciación como ilusorio.

¿Qué posición ocupa Graciela, el hablante de la diatriba, en las relaciones de poder con su oyente, el marido? Antes de su emisión, fue considerada por su esposo como un signo más de ostentación de su status burgués. En cambio, al iniciar su diatriba quiere y decide hablar en pie de igualdad, tener voz propia y ser escuchada. Será la ocasión para le comunique al marido su decisión de vivir una vida independiente, libre. Esta diatriba pide prestada su estructura de los procesos judiciales: primero se presenta la acusación, y posteriormente se adopta la sentencia, que en el presente caso consiste en la separación. Se aleja, en todo caso, del esquema argumentativo judicial si consideramos que las dos partes en conflicto no presentan sus reivindicaciones, sino sólo una de ellas. Esta diatriba es un ‘juicio’ en el que Graciela aporta pruebas sobre la irresponsabilidad y la arbitrariedad con la que su marido ha desempeñado su papel en el matrimonio. Estilísticamente, toda diatriba se detiene en la enumeración atropellada de las acusaciones que se quieren dirigir al interlocutor, como sucede con la lista anafórica expresada por Gabriela, organizada a partir de "No aguanto más [...]" (74), cerca del final del monólogo. 
En contexto latinoamericano, la diatriba matrimonial de hablante femenino se ha de entender como la ocasión para superar el silencio al que la esposa ha estado largamente confinada: supone la oportunidad para superar la 'mordaza' que ha sufrido. Es tal la sed de 'hacerse oír' de Graciela, cuya voz ha sido largamente silenciada, que las últimas palabras proferidas por ella en el monólogo expresan la necesidad de rebelarse contra una sujeción injusta y de alcanzar la libertad: “¡Déjenme hablaaaaar!” (80). Estas palabras tienen un profundo sentido simbólico, aunque se encuentren dirigidas a los músicos de una orquesta cercana cuya melodía interfiere en su monólogo: desea expresar su protesta ante el sometimiento que, como ser humano, vivió durante toda su matrimonio.

Graciela solo recibe una respuesta por parte del marido: el silencio. García Márquez quiso materializar esta indiferencia en las acotaciones escénicas para la puesta en escena, como ya dijimos, mediante la transformación de su esposo en un maniquí. Este último no tiene vida: es incapaz de escuchar y de responder. Se encuentra sentado y el hecho de que Graciela le lance una serie de recriminaciones permite asociar esta silla con el asiento de los acusados. En las diatribas caracterizadas por la actitud indignada del hablante, que exterioriza una serie de reivindicaciones por largo tiempo reprimidas, el interlocutor suele ser un oyente silencioso o que se desentiende de las reivindicaciones de la contraparte. Específicamente, la diatriba en el matrimonio se puede analizar desde la teoría del género como un acto comunicativo expresivo que una mujer expone para denunciar el machismo imperante en la cultura patriarcal latinoamericana, de cuyo representante no obtiene respuesta. El marido responde con silencio a la palabra de Graciela: “ ¡ $\mathrm{La}$ eterna víctima! Pero mientras tanto niegas a contestarme, te niegas a discutir los problemas como la gente de bien, te niegas a mirarme a la cara" (12-13); “[T]e niegas a contestarme, te niegas a discutir los problemas como la gente de bien, te niegas a mirarme a la cara" (13). 
Si bien la diatriba es un mensaje de destinatario determinado, el marido, el discurso de Graciela, en última instancia, tiene un destinatario reflexivo: el mensaje se lo dirige Graciela a sí misma ${ }^{8}$. Ya sea que el marido sea asumido como un maniquí (por el público), o como un sujeto humano desinteresado por la diatriba de su mujer (en el mundo de la ficción), en todo caso Graciela se dirige a sí misma su discurso, para convencerse de la pertinencia de sus reivindicaciones y justificar firmemente la decisión que tomará: la separación matrimonial.

Resultado, efecto o consecuencia inmediata de la diatriba es el quiebre de la relación. Supone un punto final sin posibilidad de retroceso. Graciela prende fuego al periódico, símbolo del poder patriarcal, un diario en llamas que terminará finalmente por consumir también al marido (79). Es clara la simbología de rebelión que se obtiene con la realización de este acto. Páginas atrás, otros símbolos patriarcales también recibieron el repudio de Graciela. Uno de ellos es la ropa tendida, que arroja lejos: "Arranca a manotadas la ropa seca en los alambres, y la va tirando fuera del escenario" (64). Arrojadas al inodoro, las joyas representan otro símbolo del que se despoja. Son símbolos paradigmáticos de la situación subordinada de la mujer en la estructura patriarcal burguesa.

La diatriba también se entiende, tradicionalmente, como la emisión de una serie de invectivas que incorporan diversos procedimientos de descortesía verbal. El uso de la ironía por parte de la esposa, uno de estos mecanismos, tiene por objetivo ridiculizar al interlocutor, el marido, quien ni siquiera -paradójicamente- se habría puesto a la altura de las expectativas que la sociedad patriarcal ha depositado en él. La ironía está presente en diversas ocasiones en el monólogo de Graciela: "Había que ver la temblorina de paludismo que te dio cuando oíste decir que había hecho el amor con seis de mis hombres de letras al mismo tiempo. ¡ Yo, amaestrada por mi esposo amantísimo en las delicias de la castidad!” (52). Y al comentar un caso de infidelidad de su marido, expresa: "(Con toda la ironía): Y aun así me quedaron dudas. ¿Sabes? Porque cuesta trabajo admitir que alguien tenga una amante más fea que la esposa"(48). 
Los cambios anímicos del hablante son típicos de las diatribas de contexto matrimonial. En el monólogo de García Márquez, las didascalias exponen la fluctuación del estado de ánimo de Graciela: "Se encoge de hombros" (59); "Se ríe" (59); "Se quita todo, suspirando" (70); "Hastiada" (73); "Gritando" (76); “Acelerada" (77); "Se desgañita” (80). Será común encontrar la fase del desconsuelo, cuando la esposa reconoce la distancia insalvable que separa el ideal (romántico) de la realidad (prosaica) del matrimonio en una sociedad patriarcal. En todo caso, la diatriba de Graciela también manifiesta, en otros momentos, reivindicaciones largamente reprimidas expresadas con indignación. Se alterna el desaliento y la desesperación.

Graciela se dirige al público en el llamado 'aparte teatral'. Su discurso cuenta con dos destinatarios: el marido, a quién se dirigen los reproches de la diatriba, y el espectador (lector), que en principio solo asume la función de testigo de las recriminaciones realizadas, aunque también es confidente de Graciela, como ocurre con todo soliloquio teatral. Las diatribas teatrales no solo se dirigen al destinatario directo, el objeto de las recriminaciones.

Diatriba de amor contra un hombre sentado resignifica un discurso tradicionalmente misógino, el de la diatriba tradicional, y defiende la legitimidad de un proyecto de vida propio para la mujer latinoamericana.

Alegoría de la situación de muchas esposas latinoamericanas, este texto denuncia los excesos machistas de un marido apuntalado en la comodidad de un matrimonio patriarcal. En la crítica de esta institución, la diatriba de García Márquez guarda semejanzas con la propuesta feminista de otras escritoras y escritores de la literatura latinoamericana contemporánea. La autora panameña Rosa María Britton también ha representado, como ha expuesto Chen (2007), la toma de conciencia y el desafío de la mujer burguesa y pequeña burguesa hacia el encierro hogareño y la agresión física y sexual que sufre en el patriarcado ${ }^{9}$. Britton resignifica el modelo genérico
Conclusiones: Resignificación de la diatriba misógina de la tradición literaria occidental 
El acto de habla de la diatriba de hablante femenino en un ...

tradicional del melodrama, que Monsiváis (1994) ha estudiado tanto en la literatura como en el cine. Sin llegar a adoptar las tácticas reivindicativas de los movimientos feministas, mujeres inicialmente limitadas al papel hogareño del ama de casa en los relatos de Britton llegan a problematizar los roles sexistas que la sociedad patriarcal les ha impuesto (Santiago-Stommes, 2007). Asimismo, Graciela, en el monólogo de García Márquez, también se encuentra en esta fase de la liberación femenina: antes de optar por modelos alternativos de experiencia femenina, decide liberarse, en primer lugar, de las normas patriarcales.

La narrativa sentimental tradicional siempre ha representado la narrativa del noviazgo (Sarlo, 2011), una más entre las prácticas amorosas, aquellas que en conjunto Martín Gaite (1987a; 1987b) ha investigado en dos oportunidades. En cambio, podemos afirmar que aquellos relatos y novelas que critican la presión machista de la sociedad sobre la conducta de la mujer representan la fase del matrimonio, como se ha demostrado en el presente análisis de Diatriba de amor contra un hombre sentado, de García Márquez. 
1. Fue estrenada por primera vez el 20 de agosto de 1988 en Buenos Aires. A continuación, se estrenó en Colombia en 1994 y en España en el 2004. Así se señala en la información que ofrece la editorial Mondadori - antes del inicio del texto dramático- sobre las escenificaciones de este monólogo.

2. El presente caso nos recuerda también la proyección transgénero que se suele dar muchas veces en el género poético del monólogo dramático. Por ejemplo, Alfred Tennyson cuenta con monólogos dramáticos en los que el hablante es una mujer, mientras que Elisabeth Barrett-Browning tiene monólogos en los que el enunciador es un hombre. Se analiza el monólogo dramático transgénero [cross-gendered monologues] en Byron (2003, 74-80).

3. Dos posibilidades consisten en emplear el estilo directo parodiado o el estilo indirecto. Véase, al respecto, Bajtín (1986).

4. En otros soliloquios, el interlocutor permanece mudo por otros motivos: así, en Cinco horas con Mario (1966), de Miguel Delibes, emitido por una viuda, el marido no contesta porque ha fallecido.

5. Véase, por ejemplo, Puig Rodríguez-Escalona (1994) y Donoso Rodríguez (2008).

6. García Márquez, Gabriel. 2004. Diatriba de amor contra un hombre sentado. Barcelona, España: Mondadori, p. 11.

7. Para establecer una distinción entre la mentira y la mala fe se puede consultar: Jean-Paul Sartre, El ser y la nada. Ensayo de ontología fenomenológica, Buenos Aires, Losada, 1984.

8. He tomado de Jean-Marie Schaeffer (2006, 68-70) ambas categorías conceptuales. El teórico francés distingue, por una parte, el destinatario determinado y el indeterminado, y por otra, el destino transitivo y el reflexivo.

9. Así ocurre en novelas como Todas íbamos a ser reinas (1997), y en cuentos como "Hechizo de amor" (de título irónico) y "El ritual de los Arcángeles", de la colección ‘La nariz invisible’ y otros misterios (2000). 
El acto de habla de la diatriba de hablante femenino en un ...

Austin, John. (2009). Cómo hacer cosas con palabras. Barcelona: Paidós.

Bajtín, Mijail. (1986). Problemas literarios y estéticos. La Habana: Editorial Arte y Literatura.

Byron, Glennis. (2003). Dramatic Monologue. London: Routledge.

Britton, Rosa María. (2000). La nariz invisible y otros misterios. Madrid: Editorial Torremozas.

Chen Sham, Jorge. (2007). "La cultura popular en La nariz invisible y otros misterios: la función de la "brujería” y el melodrama. En: Humberto López Cruz (ed.). Rosa María Britton ante la crítica. Madrid: Editorial Verbum, 66-78.

Donoso Rodríguez, Miguel. (2008). "Mujer y misoginia en tres textos medievales españoles", Taller de Letras, 43, 121-130.

García Márquez, Gabriel. (2004). Diatriba de amor contra un hombre sentado. Barcelona, España: Mondadori.

García Márquez, Gabriel. (2012). Todos los cuentos. Barcelona: Mondadori.

Gilbert, Sandra M. y Susan Gubar. (1998). La loca del desván. La escritora y la imaginación literaria del siglo XIX. Madrid: Cátedra.

López Cruz, Humberto (ed.). (2007). Rosa María Britton ante la crítica. Madrid: Editorial Verbum.

Martín Gaite, Carmen. (1987a). Usos amorosos del dieciocho en España. Barcelona: Anagrama.

Martín Gaite, Carmen. (1987b). Usos amorosos de la postguerra española. Barcelona: Círculo de Lectores. 
Monsiváis, Carlos. (1994). "Se sufre, pero se aprende". En: Carlos Monsiváis y Carlos Bonfill. A través del espejo. El cine mexicano y su público. México: Ediciones El Milagro/Instituto Mexicano de Cinematografía, 99-224.

Pavis, Patrice. (1998). Diccionario de teatro. Barcelona: Paidós.

Puig Rodríguez-Escalona, Mercè. (1994). "Poemas misóginos proverbiales en la Edad Media latina: Arbore sub quadam dictavit clericus Adam, Femina formosa scelus et pestis vitiosa y De artificiosa malitia mulieris", Faventia, Vol. 16 (2).

Real Academia Española. (2001). Diccionario de la Lengua Española. Tomo I (Vigésima segunda edición). Madrid: Real Academia Española.

Santiago-Stommes, Ivelisse. (2007). “¿Liberación o prisión? El movimiento de liberación femenina cuestionado en "Semana de la mujer" y otras calamidades de Rosa María Britton”. En: Humberto López Cruz (ed.). Rosa María Britton ante la crítica. Madrid: Editorial Verbum, 54-65.

Sarlo, Beatriz. (2011). El imperio de los sentimientos. Narraciones de circulación periódica en la Argentina. Buenos Aires: XXI Editores.

Sartre, Jean Paul. (1984). El ser y la nada. Ensayo de ontología fenomenológica. Buenos Aires: Losada.

Schaeffer, Jean-Marie. (2006). ¿Qué es un género literario? Madrid: Akal.

Searle, John. (1975). “A classification of illocutionary acts", Language in Society, $5,1-23$.

Solomon, Irvin D. (1993). "Latin American Women in Literature and Reality: García Márquez's One Hundred Years of Solitude”, The Midwest Quarterly, 34(2), 192-205. 